\title{
COMPARISON OF WHEAT DRYING PROCESS DYNAMICS AT DIFFERENT VENTILATION SPEEDS
}

\author{
Janis Palabinskis, Aivars Aboltins \\ Latvia University of Life Sciences and Technologies, Latvia \\ janis.palabinskis@1lu.lv, aivars.aboltins@1lu.lv
}

\begin{abstract}
The aim of the study was to determine the drying dynamics of cereals under laboratory conditions depending on the layer thickness by actively ventilating with constant ambient air parameters. The average air temperature in the laboratory room during drying was $20.8{ }^{\circ} \mathrm{C}$ and the average relative humidity was $36 \%$. Wheat was divided into four elementary layers. Their moisture at the beginning of drying averaged $17 \%$, but at the end of drying it averaged $13.2 \%$. Wheat was simultaneously dried by active aeration with the following air filtration rates: $0.33 \mathrm{~m} \cdot \mathrm{s}^{-1}, 0.42 \mathrm{~m} \cdot \mathrm{s}^{-1}, 0.54 \mathrm{~m} \cdot \mathrm{s}^{-1}$ and $0.61 \mathrm{~m} \cdot \mathrm{s}^{-1}$. At the beginning of the drying process, a rapid removal of moisture from the material to be dried was detected, which contributed to a rapid drop in temperature. Moisture removal of wheat throughout the layer thickness was independent of the aeration air velocity and was approximately 3.7 grams per 100 grams of grain. The highest electricity consumption for carrying $1 \mathrm{~g}$ of water per $100 \mathrm{~g}$ of wheat in the whole layer thickness was found at the air filtration speed of $0.61 \mathrm{~m} \cdot \mathrm{s}^{-1}$ was $32 \mathrm{Wh}$, but with the air filtration speed of $0.33 \mathrm{~m} \cdot \mathrm{s}^{-1}$, it was consumed 3 times less, respectively $11 \mathrm{Wh}$.
\end{abstract}

Keywords: wheat, drying, ventilation speed.

\section{Introduction}

For wheat and other cultivated cereals, drying and storage methods affect crop quality and the yield. Drying methods are particularly important when processing cereals and other agricultural products. On the other hand, the drying process consumes a large amount of energy.

Drying operations alone account more that $10 \%$ of the overall pattern of energy usage in food and agriculture. French industry uses $6.3 \cdot 10^{9} \mathrm{MJ} \cdot \mathrm{y}^{-1}, \mathrm{UK}-35 \cdot 10^{9} \mathrm{MJ} \cdot \mathrm{y}^{-1}$, it was approximately $12 \%$ and $20-25 \%$ in Germany and Denmark $[1 ; 2]$.

The drying systems currently used meet the basic functional requirements, but they do not achieve sufficient energy consumption, environmental pollution, product quality, ease of operation, safety and management criteria. Energy resources are limited, and a resource-efficient grain dryer needs to be developed as a matter of urgency.

Drying can be done by natural convection or forced convection. The first major limitation is slowness and weather conditions. Forced drying is an artificial process designed to remove excess moisture to the limit of the chemical, biological and functional properties of the grain. This method usually uses forced air flow with heated or slightly heated air. Drying grain with not too warm air, even if it is not so fast, preserves wheat with better properties than drying at a higher temperature, which increases the speed of the process, but it can damage the grain. Low temperature drying does not create conditions for separation of grains from certain volatile substances, contributing to the stability of the original properties of the product.

The external heat and mass transfer rate increase as the airflow rate and temperature increase, or as humidity decreases. Any measure to reduce external resistance will result in an increase in the drying rate $[3 ; 4]$.

In turn, by studying the influence of the air temperature and air flow in the drying process, the evaporation of the amount of water containing the drying material was studied using a special drying equipment with a fan and a heating element. According to the results of the study, it was concluded that increasing the temperature and higher air flow speed accelerates the process of water evaporation from the drying material. However, when drying the material at high temperatures, the effect of temperature on evaporation is significantly smaller [5].

At the beginning of the drying process, the evaporation rate of water is quite high, but it tends to decrease during the rest of the drying process. Therefore, it was concluded that the evaporation process requires more energy at a time when the material to be dried has a relatively low water content [6].

The effect of grain temperature and density on wheat drying kinetics was experimentally studied in the laboratory. The study was performed with a drying temperature of 40,45 and $50{ }^{\circ} \mathrm{C}$ and a density of 2.12 and $4.24 \mathrm{~kg} \mathrm{~m}^{-2}$ at a constant air speed of $0.6 \mathrm{~m} \cdot \mathrm{s}^{-1}$. It was found that the drying time decreased 
with increasing the drying temperature at a certain humidity ratio. In turn, the increased grain density worsened the drying process rate, so it is desirable to dry grain with a lower density or a thinner layer [7].

Several thin layers theoretically form one thick layer [7]. During the drying process, each layer through which the air flows changes the quality of the flowing air, so that only the first layer receives a constant air flow, reducing the moisture content of the grain layer faster than the other layers [8].

Thin-layer drying is an effective drying laboratory test for grains that are primarily used to find constants for drying or empirical equations. Several empirical equations and models have been developed in the literature to describe the drying process. However, all these equations are incomplete because they do not specify the drying process. Their limitations are a small temperature range, the air flow is not fully taken into account, or they do not allow to change the parameters of the drying process. Therefore, usually for complex equations, several unknowns are assumed to be constant. It is also generally assumed that drying is an isothermal process where only the diffusion coefficient is used to describe the drying dynamics [9-11].

Today, drying equipment plays an important role in the processing and storage of various food and other materials. Due to the high energy consumption of the drying process, special attention is paid to the efficiency of the drying equipment and its cost to sustainable development [12]. The report on tray drying of agricultural products emphasizes the importance of ensuring optimal drying conditions for a small amount of material to be dried, mainly various grasses, leaves, etc. [13-16]. The type of drying and the design of the plant have a significant effect on the quality of the dried product $[17 ; 18]$

The tray drying apparatus consists of a number of small trays, which are placed in an insulated chamber in which heated air is supplied and air is supplied with or without a fan. In some cases, the exhaust air from the dryer is partially returned to the chamber. Trays in such equipment may be stationary or moving in a certain direction [17].

In the Abu-Hamdeh and Othman study on wheat drying, a drying process was performed with grains that were crushed in containers in three layers, and the air flow was introduced into these layers at certain temperatures. The drying unit consisted of a drying chamber, an air conditioner with a constant air flow, temperature, and relative humidity. The results showed that the simulation of the drying process is in agreement with the results obtained in the experiment. However, the simulation showed that the temperature between the layers was slightly higher than in the experiment [19].

Grain drying is a process that usually removes a small amount of water from the grain Thick bed dryers are one of the most commonly used industrial dryers. Drying of a thick layer refers to drying of heterogeneous grains in a thick layer deeper than $20 \mathrm{~cm}$. When air is introduced into the bottom of the grain layer, these grains are usually dried, but at the top of the layer they are still moist. It is assumed that drying in a thick layer consists of several thin layers placed one on top of the other, usually in the direction of the air flow [19].

The results of Souza and Miranda's study on the drying process of soybeans in a thick layer show that in the mathematical model the numerical results are in agreement with the measurement results, which makes it possible to predict the drying process of soybeans by drying in a thick layer. The heterogeneity of the drying process in the thick layer was also analyzed [20].

As mentioned above, an important factor in drying is energy reduction. Therefore, this study compared the drying process of wheat grain at different air speeds at non-heated air temperature.

\section{Materials and methods}

To carry out the research, a four-section experimental device was built for simultaneous drying in layers with fans of different capacities. The dimensions of each section were $282 \times 282 \times 480 \mathrm{~mm}$ and the total size of the device was $600 \times 600 \times 520 \mathrm{~mm}$ (Fig. 1).

The operation of the drying device was as follows (Figure 2): the wet drying material was collected in four cylindrical containers with a sieve base and placed on the device. For the experiment, 4 cylindrical trays were placed on each section, forming 4 layers.

$12 \mathrm{~V}$ fans with different parameters were used for each section: with 900, 1200, 200, and $2900 \mathrm{rpm}$; with air flow rates of $253,210,180$, and $190 \mathrm{~m}^{3} \cdot \mathrm{h}^{-1}$. Ventilation drying was performed by means of air 
overpressure. To determine the drying dynamics, the air temperature and relative humidity of the layers and the air filtration rate through the layers of the material to be dried were measured, as well as the water output was determined by weighing the material to be dried in each layer. Data measurements were performed using a KM120 data logger with 16 sensors, of which 12 were the temperature sensors TSIC 506 and 4 temperature and humidity sensors HYT 939. The measuring equipment used in the studies and its technical data are given in Table 1.
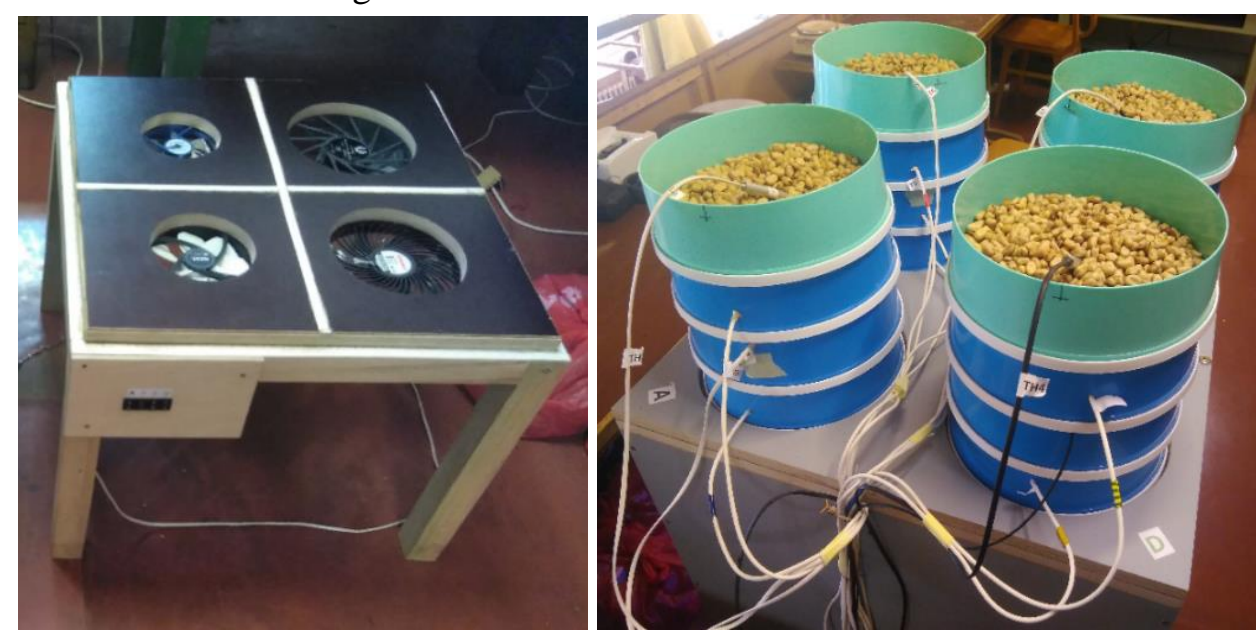

Fig. 1. Laboratory equipment, fan block and wheat drying

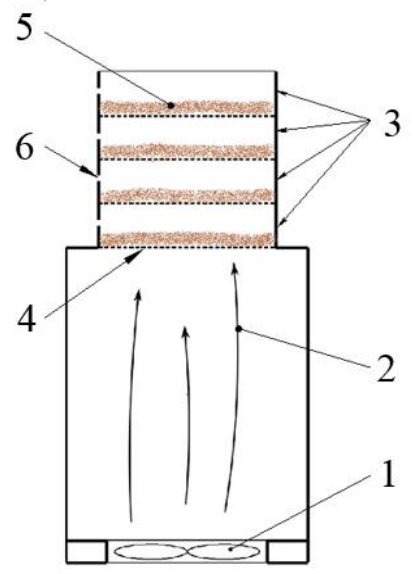

Fig. 2. Laboratory equipment, one-section work scheme: 1 - fan; 2 - air flow; 3 - cylindric trays; 4 - sieve base; 5 - wheat grains; 6 - holes for inserting sensors

The studies were performed under laboratory conditions, therefore the average room air temperature and average relative humidity were taken into account. At the beginning of drying, an average of $400 \mathrm{~g}$ of wheat (moisture 17\%) was poured into one cylindrical container. The total weight of wheat in 16 cylindrical containers was $6.42 \mathrm{~kg}$. Every 1 hour, all trays were weighed and the amount of water removed was recorded.

Table 1

Equipment and measuring instrument parameters

\begin{tabular}{|l|c|c|}
\hline \multicolumn{1}{|c|}{ Equipment, unit } & Measuring range & Accuracy \\
\hline Anemometer Mastech MS6252B, $\mathrm{m} \cdot \mathrm{s}^{-1}$ & $0.8-30$ & \pm 0.6 \\
\hline Humidity meter Super Tech SuperPro, $\%$ & $5-50$ & \pm 0.25 \\
\hline Scales KERN EW 1500-2M, g & $0-1500$ & \pm 0.01 \\
\hline KM 120, temperature sensor TSIC $506,{ }^{\circ} \mathrm{C}$ & $-10-+60$ & \pm 0.1 \\
\hline KM 120, temperature and relative humidity & $-40-+125$ & \pm 0.2 \\
\cline { 2 - 3 } sensor HYT 939, ${ }^{\circ} \mathrm{C}$ & $0-100$ & $\pm 1.8\left(\right.$ at $\left.23^{\circ} \mathrm{C}\right)$ \\
\hline
\end{tabular}


Wheat drying time lasted for 6 hours. Drying was performed under laboratory conditions with an average air temperature of $21 \pm 1{ }^{\circ} \mathrm{C}$ and an average relative humidity of $36 \pm 2 \%$. For the analysis of the results, the water output per $100 \mathrm{~g}$ for each drying material was calculated separately for the layers and the total water output depending on the layer thickness using formula (1):

$$
Q=\frac{m_{0}-m_{i}}{m_{0}} \cdot 100 \mathrm{~g},
$$

where $Q$ - water output, g. $(100 \mathrm{~g})^{-1}$;

$m_{0}$ - initial weight of the material to be dried before drying, g;

$m_{i}$ - weight of the material during drying, $\mathrm{g}$.

MathCad and MatLab mathematical programs were used to process the given experimental data and determine relationships.

\section{Results and discussion}

In the drying process of wheat after 3 hours (Fig. 3) using unheated air it can be seen that in the section with the highest air flow rate, which is $0.61 \mathrm{~m} \cdot \mathrm{s}^{-1}$, the drying temperature in all 4 layers already exceeds the room air temperature or the inlet air temperature. installation. In turn, a similar situation is observed in the compartment with an air flow rate of $0.54 \mathrm{~m} \cdot \mathrm{s}^{-1}$, where the room air temperature in all layers was exceeded only at the end of drying, that is, after 5 hours. Significant temperature differences are observed in the compartment with the lowest air flow rate, which is $0.33 \mathrm{~m} \cdot \mathrm{s}^{-1}$, where layers 3 and 4 have the smallest temperature rise compared to layers 1 and 2. This shows that in layers 1 and 2 the wheat is dehydrated, while layers 3 and 4 are still wet.

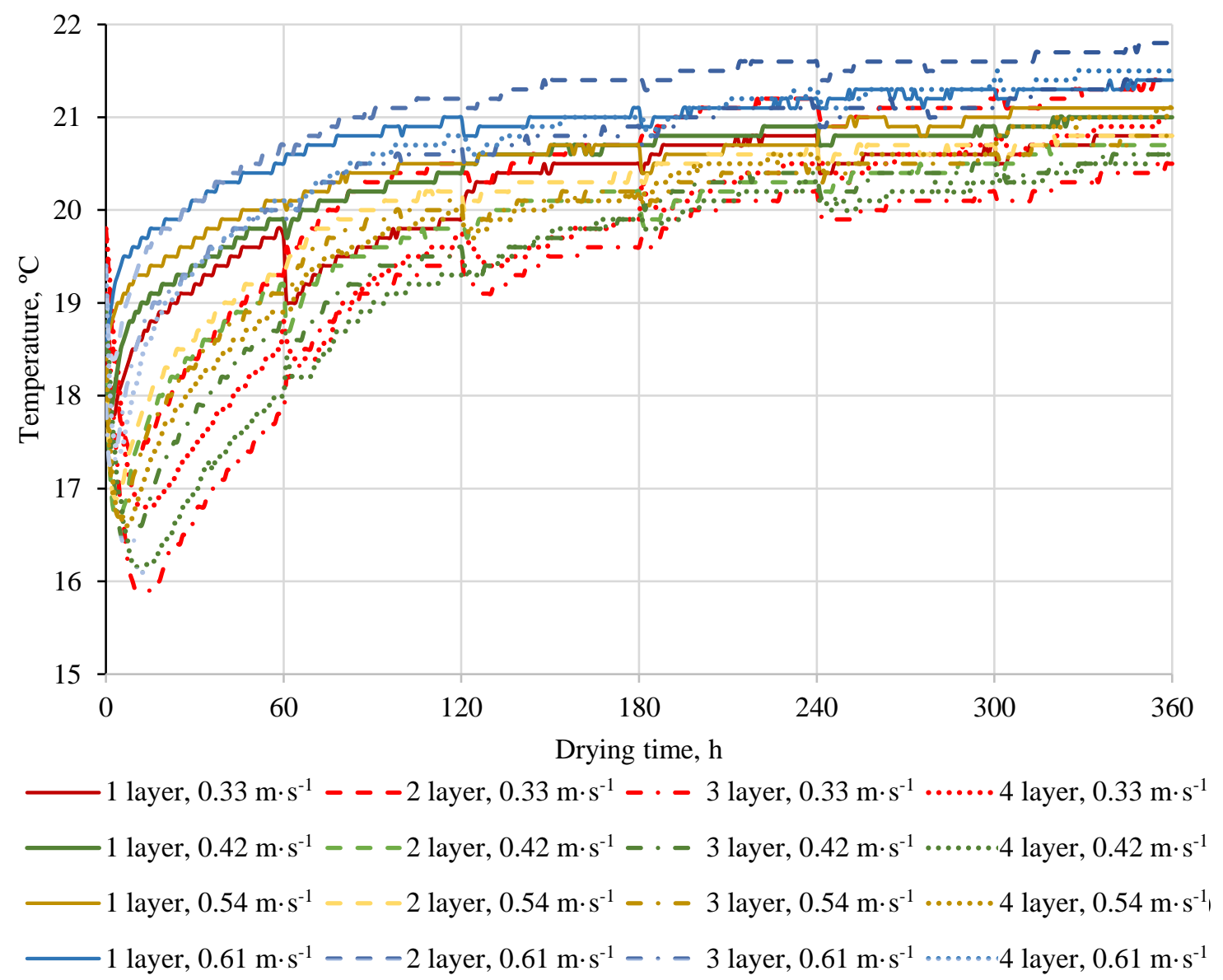

Fig. 3. Air temperature changes during wheat drying, ${ }^{\circ} \mathrm{C}$ 
The relative humidity of the air during drying was measured in compartments with air flow rates of $0.33 \mathrm{~m} \cdot \mathrm{s}^{-1}$ and $0.61 \mathrm{~m} \cdot \mathrm{s}^{-1}$ (Fig. 4). At the beginning of drying there is a more rapid decrease of humidity, but in the following time there is a gradual decrease of relative air humidity to room air humidity, which was $36 \%$. This clearly showed that the water removal decreases significantly at the end of drying, as the incoming drying air is no longer able to absorb moisture from the wheat efficiently.

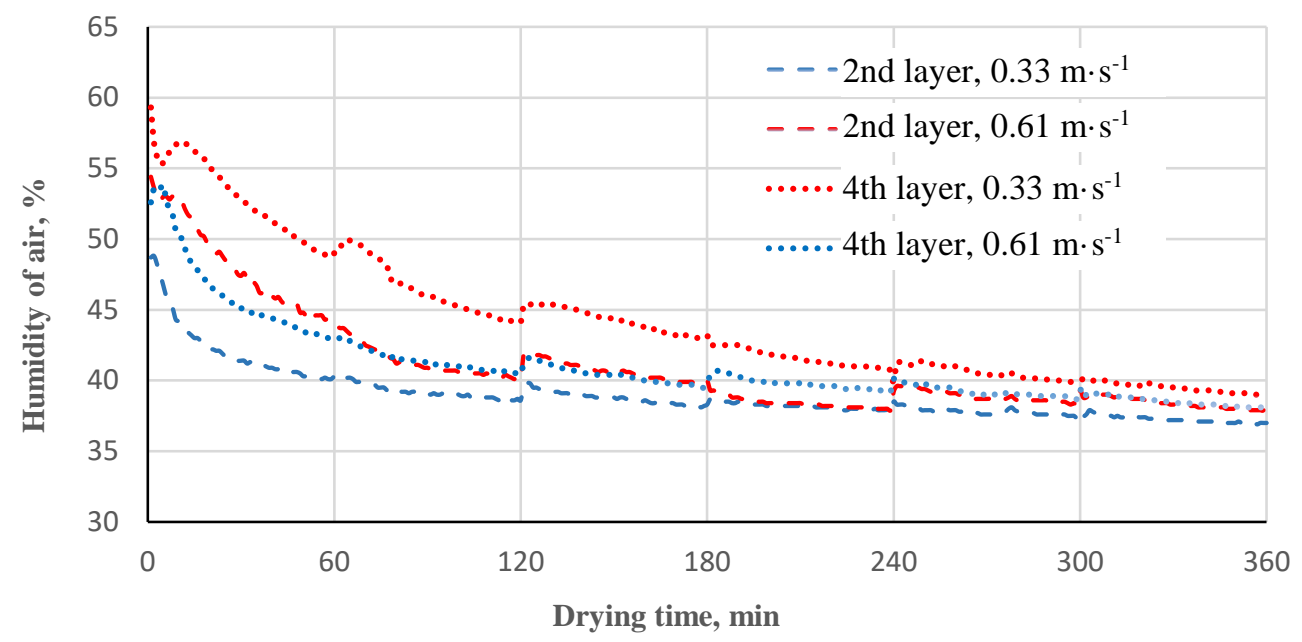

Fig. 4. Ventilation air relative humidity changing during wheat drying, $\%$

Evaluating the water removal, a close relationship is observed between the layers and the air filtration rates. At an air filtration rate of $0.33 \mathrm{~m} \cdot \mathrm{s}^{-1}$, layers 3 and 4 had the lowest water output, which were 3.50 and $3.57 \mathrm{~g}(100 \mathrm{~g})^{-1}$, respectively. Compared to the other layers, the difference in water outlet is insignificant, which means that the change in the air filtration rate does not significantly affect the drying rate and water outlet, and wheat is a relatively porous material and does not cause significant resistance to the fan airflow. Wheat moisture averaged $17 \%$ at the beginning of drying and $13.2 \%$ at the processing of the experimental data, the correlations between the dependence of the extracted water on the layer thickness and the velocity of the ventilated air and the drying time were obtained.

The amount of water removed during drying of wheat by hours, depending on the layer thickness at the air filtration rate $0.33 \mathrm{~m} \cdot \mathrm{s}^{-1}, \mathrm{~g}(100 \mathrm{~g})^{-1}$ is shown in Fig.5. It can be seen here that at the beginning of drying, the largest amount of water is removed in the 1st hour, but in the following hours it decreases rapidly. Considering the layer thickness, the thinner layer has on average higher water output than the thicker layer, but in wheat drying at the air filtration speed of $0.61 \mathrm{~m} \cdot \mathrm{s}^{-1}$ (Fig. 6) there is a slightly more uniform water output over the whole layer thickness, but this difference is minimal, therefore no significant difference in humidity was observed for dried wheat at different air filtration rates.

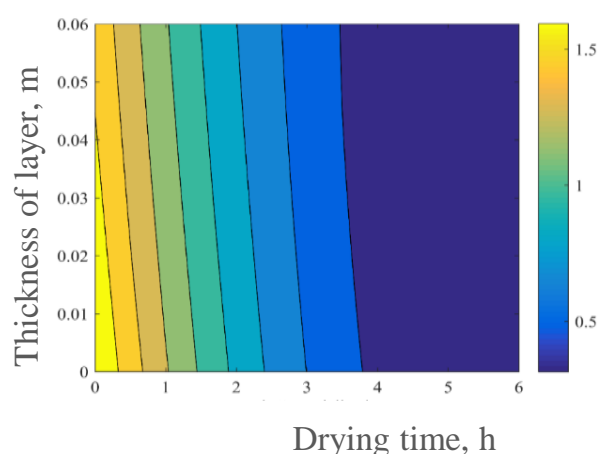

Fig. 5. Amount of water removed for wheat per $100 \mathrm{~g}$ per hour depending on the layer thickness at the air filtration rate of $0.33 \mathrm{~m} \cdot \mathrm{s}^{-1}$

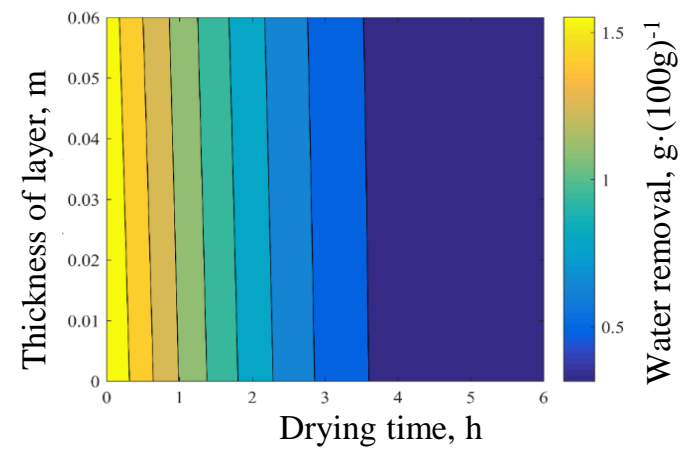

Fig. 6. Amount of water removed for wheat per $100 \mathrm{~g}$ per hour depending on the layer thickness at the air filtration rate of $0.61 \mathrm{~m} \cdot \mathrm{s}^{-1}$ 
Using the air filtration rate of $0.61 \mathrm{~m} \cdot \mathrm{s}^{-1}$ for drying wheat, it can be seen that the water removal per $100 \mathrm{~g}$ per hour practically does not change depending on the layer thickness, that is, it is the same throughout the layer thickness. Thus, the dependence of water output on the drying time and layer thickness is linear at higher air filtration rates. The results show that in the 1st hour of drying the highest amount of water per $100 \mathrm{~g}$ is removed, while the minimum amount of water is observed after the 3rd hour, when the wheat moisture dropped to $13.8 \%$ on average, while after 6 hours the average wheat moisture reached $13.2 \%$.

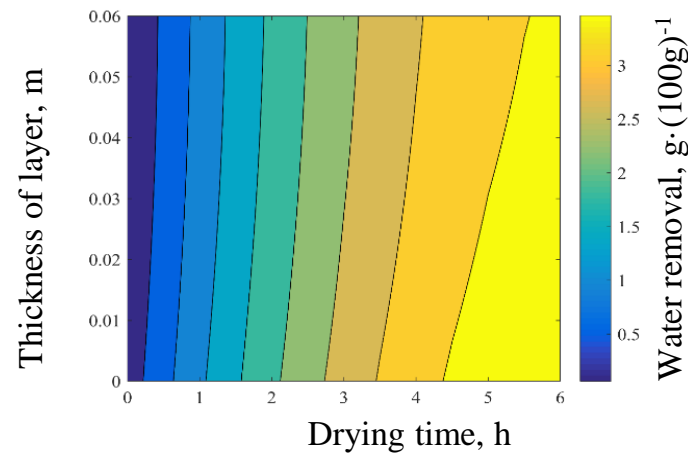

Fig. 7. Total water output for $100 \mathrm{~g}$ wheat depending on the layer thickness and drying time at an air filtration rate of $0.33 \mathrm{~m} \cdot \mathrm{s}^{-1}$

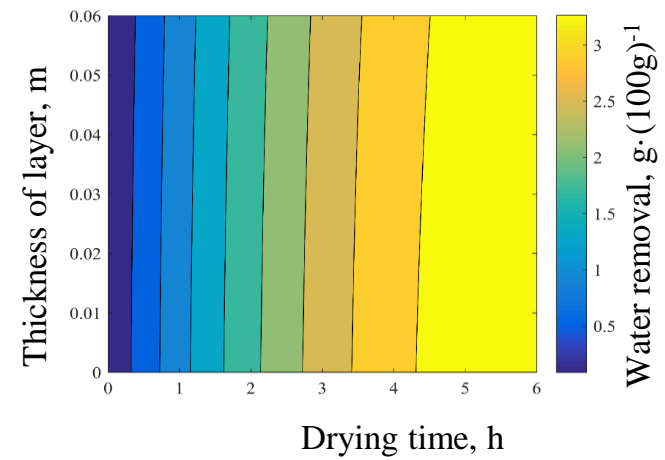

Fig. 8. Total water output for $100 \mathrm{~g}$ wheat depending on the layer thickness and drying time at an air filtration rate of $0.61 \mathrm{~m} \cdot \mathrm{s}^{-1}$

For wheat, there is no significant difference in the total water output per $100 \mathrm{~g}$ during the drying process. Comparing the results of Fig. 7 and Fig. 8, at lower and higher air filtration speed there is a small effect of layer thickness on water discharge, that is, at $0.33 \mathrm{~m}^{\mathrm{s}-1}$ air filtration rate, as the layer thickness increases, water removal slightly decreases, but at $0.61 \mathrm{~m}^{\mathrm{s}-1}$ water removal is markedly smoother, but overall, the difference is minimal.

There is no significant difference in electricity consumption between layers 1,2, 3 and 4 . during drying wheat by the active ventilation method. This indicates that the air filtration rate, in this case, does not significantly affect the water removal in each layer, because the energy consumed in all layers $(1 \mathrm{~g}$ water vs $100 \mathrm{~g}$ grain) is similar.

The thin layer thickness does not cause high air resistance at any of the air filtration rates used in the experiments. At higher air flow rates, e.g., $0.42 \mathrm{~m} \cdot \mathrm{s}^{-1}$, the difference in power consumption is correspondingly larger, depending on the fan power used, the air filtration speeds of $0.54 \mathrm{~m} \cdot \mathrm{s}^{-1}$ and 0.61 $\mathrm{m} \cdot \mathrm{s}^{-1}$ have a similar trend. As the layer thickness does not significantly affect the drying of wheat, it is worth using a lower air filtration rate when drying wheat with active aeration during the whole drying period, but given the total layer thickness of $6 \mathrm{~cm}$, practically wheat is dried in a much thicker layer and the drying process in such a layer may change significantly and may not correspond to these study results.

Electricity consumption increased by an average of 3-4 Wh per hour. This means that the water output per $100 \mathrm{~g}$ decreases with each hour during drying, as the moisture content of the wheat approaches the moisture of the condition, and when the wheat is actively ventilated, the air temperature and relative humidity are not sufficient to increase the water output during the drying process.

Drying wheat in a thick layer there is no big difference in electricity consumption in individual layers. Therefore, the wheat dried evenly throughout the thickness of the layer, regardless of the air filtration rate. As well as in the 1 st hour of wheat drying time, as the air filtration rate increases, so does the electricity consumption.

Figure 9 shows the total electricity consumption per hour for $1 \mathrm{~g}$ of water per $100 \mathrm{~g}$ grain depending on the air filtration rate over the entire thickness of the wheat layer. 


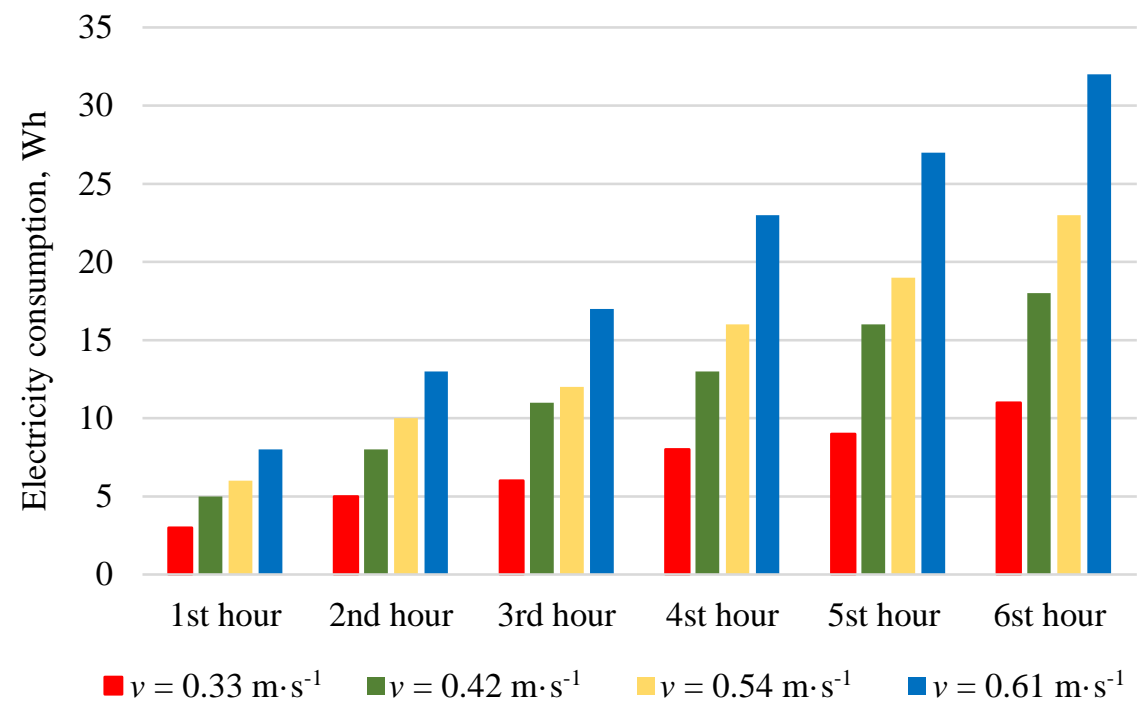

Fig. 9. Total electricity consumption for wheat per hour for $1 \mathrm{~g}$ of water per $\mathbf{1 0 0} \mathrm{g}$ grain depending on the air filtration rate throughout the layer thickness

\section{Conclusions}

1. At the beginning of the drying process a rapid removal of water from the grains was found, which contributes to a rapid drop in temperature.

2. Air filtration speeds $\left(0.33,0.42,0.54\right.$ and $\left.0.61 \mathrm{~m} \cdot \mathrm{s}^{-1}\right)$ had a small effect on the dynamics of the wheat drying process. The tendency of water removal changes, depending on the layer thickness during drying, is similar.

3. Water removal per $100 \mathrm{~g}$ wet wheat grain in the whole layer thickness at air filtration rates 0.33 , $0.42,0.54$ un $0.61 \mathrm{~m} \cdot \mathrm{s}^{-1}$ are $3.64,3.71,3.74,3.69 \mathrm{~g}(100 \mathrm{~g})^{-1}$, respectively.

4. The highest electricity consumption for carrying $1 \mathrm{~g}$ of water per $100 \mathrm{~g}$ of wheat in the whole layer thickness was found at the air filtration speed of $0.61 \mathrm{~m} \cdot \mathrm{s}^{-1}$, it was $32 \mathrm{Wh}$, but with the air filtration speed of $0.33 \mathrm{~m} \cdot \mathrm{s}^{-1}$ it was consumed 3 times less, respectively $11 \mathrm{Wh}$.

\section{References}

[1] Stumillo C., Jones P., Zulla R. Energy aspects in drying. Chapter in Handbook of Industrial drying, 2014, pp. 1075-1101.

[2] Page C. Factors Influencing the Maximum Rate of Drying Shelled Corn in Layers. M.S. Thesis, Purdue University, 1949. [online] [21.03.2021] Available at: https://ci.nii.ac.jp/naid/10024350307/

[3] Hemis M., Singh C B., Jayas D S., Bettahar A. Simulation of coupled heat and mass transfer in granular porous media: Application to the drying of wheat. Drying Technology, 29(11), 2011, pp. 1267-1272. DOI:10.1080/07373937.2011.591712

[4] Qin Y., Fu H., Wang J., Liu M., Yan J. Waste heat and water recovery characteristics of heat exchangers for dryer exhaust. Dry Technology, 36(6), 2017, pp. 1-14.

[5] Sun Y., Guo X., Xu B., Wang C., Wang Y., Jiao Y., Li S., Ying J., Liu X. Design and test of a novel wheat drying oven based on the real-time utilization of diesel engine waste heat, Cogent Engineering, 10 p. 6:1, 2019, 1673118, DOI: 10.1080/23311916.2019.1673118

[6] Putra R. N., Ajiwiguna T. A. Influence of Air Temperature and Velocity for Drying Process. Procedia Engineering, 170, 2017, pp. 516-519. DOI: 10.1016/j.proeng.2017.03.082

[7] Hosain M., Haque R., Islam M. N., Khatun H., Shams-Ud-Din M. (2016). Effect of temperature and loading density on drying kinetics of wheat. Journal of Experimental Biology and Agricultural Sciences, 4(2), pp. 210-217. DOI: 10.18006/2016.4(2).210.217

[8] Jayas D. S., Cenkowski S., Pabis S., Muir W. E. Review of thin-layer drying and wetting equations. Drying Technology, 9(3), 1991, pp. 551-588. DOI: 10.1080/07373939108916697

[9] Martínez D., Alonso J. Modeling of Grain Dryers: Thin Layers To Deep Beds, 2011. 
[10] Aboltins A. Theoretical study of material drying coefficient /12th International scientific conference "Engineering for rural development": proceedings, Jelgava, Latvia, May 23-24, 2013 / Latvia University of Agriculture. Faculty of Engineering. Jelgava, 2013. pp. 153-158.

[11] Aboltins A., Rubina T., Jotautiene E. Diffusion coefficient estimation difficulties at the beginning of drying experiment. 16th International scientific conference "Engineering for rural development": proceedings, Jelgava, Latvia, May 24-26, 2017 / Latvia University of Agriculture. Faculty of Engineering. Latvian Academy of Agricultural and Forestry Sciences. Jelgava, 2017 Vol.16, pp. 1327-133.

[12] Mujumdar A. S. Handbook of industrial drying. (A. S. Mujumdar, Ed.). CRC press., 2014, 1318 p.

[13] Kic P., Aboltins A. Drying process of two special plants/13th International scientific conference "Engineering for rural development": proceedings, Jelgava, Latvia, May 29-30, 2014 / Latvia University of Agriculture. Faculty of Engineering. Jelgava, 2014. Vol. 13, pp. 137-142.

[14] Aboltins A., Kic P. Research in medical plant drying process /15th International scientific conference "Engineering for rural development": proceedings, Jelgava, Latvia, May 25-27, 2016 / Latvia University of Agriculture. Faculty of Engineering. Jelgava, 2016. Vol.15, pp. 1145-1150.

[15] Aboltins A. Tomsu J., Kic P. Red clover drying coefficient dependences on air velocity at constant drying temperature // Agronomy Research. Vol.16(2) (2018), pp. 313-319.

[16] Aboltins A., Kic P. Influence of air velocity on drying dynamics of alfalfa /17th International scientific conference "Engineering for rural development": proceedings, Jelgava, Latvia, May 2325, 2018 / Latvia University of Life Sciences and Technologies. Faculty of Engineering. Latvian Academy of Agricultural and Forestry Sciences. Jelgava, 2018. Vol. 17, pp. 1470-1475.

[17] Misha S., Mat S., Ruslan M. H., Sopian K., Salleh E. Review on the application of a tray dryer system for agricultural products. World Applied Sciences Journal, 22(3), 2013, pp. 424-433. DOI: 10.5829/IDOSI.WASJ.2013.22.03.343

[18] Paulo C., Coradi P., Fernandes C., Helmich J., Goneli A. Effects of drying air temperature and grain initial moisture content on soybean quality (Glycine max (L.) merrill) Journal of the Brazilian Association of Agricultural, v.36, n.5, 2016, pp. 866-876.

[19] Abu-Hamdeh N. H., Othman A. M. An Experimental Study and Mathematical Simulation of Wheat Drying. Drying Technology, 22(3), 2004, pp. 491-506. DOI: 10.1081/DRT-120029995

[20] Souza G. F. M. V., Miranda R. F., Lobato F. S., Barrozo M. A. S. Simultaneous heat and mass transfer in a fixed bed dryer. Applied Thermal Engineering, 90, 2015, pp. 38-44. DOI: 10.1016/j.applthermaleng.2015.06.088 